\title{
Perfil das universidades brasileiras de e com potencial de classe mundial
}

\author{
Luiz Alberto Pilatti
}

Marizete Righi Cechin

\begin{abstract}
Resumo: $\mathrm{O}$ texto tem por objetivo analisar o perfil das universidades brasileiras que estão na condição de Universidade de Classe Mundial (UCM) e as com potencial para atingir essa condição. O estudo é documental com características exploratórias. O corpus documental é composto pelos rankings Academic Ranking of World Universities (ARWU), Times Highter Education Ranking (THE) e Quacquarelli Symonds World University Ranking (QS), divulgados no período de 2011-2015; pelos dados fornecidos pela rede mundial de computadores nos anuários da UERJ, UNICAMP, USP e UNESP; no orçamento de São Paulo 2014, nos dados da CAPES (2015), no INEP e nos sítios das universidades. Constata-se três universidades consolidadas na condição de UCM (USP, Unicamp e UFRJ) e três em consolidação (UNESP, UFRGS e UFMG). A UNESP, a UFRGS e a UFRJ têm tendência ascendente nos rankings; a USP, a Unicamp e a UFMG têm tendência descendente. Constata-se potencial para atingir a condição de UCM em 11 universidades: PUC-RJ, PUC-RS, UERJ, UFBA, UFPR, UFSC, UFSCar, UTV, UnB, PUC-SP e a Unifesp. As UCM brasileiras são públicas, com média de idade de 72 anos e com percentual de 76,49 de alunos na graduação e 23,51\% na pós-graduação. O estado de São Paulo apresenta o maior percentual de alunos de pós-graduação e um nível mais elevado de investimento (custo anual por aluno). Conclui-se que as universidades que pertencem à Classe Mundial apresentam em comum publicações em periódicos indexados em base de dados como a SCIE, a SSCI, a Thomson Reuters e o Scopus.
\end{abstract}

Palavras-chave: Universidade. Critérios dos ranking. Classe mundial.

\section{Profile of Brazilian World Class and potential World Class universities}

Abstract: The text aims to analyze the profile of Brazilian universities that are in the World Class University condition (UCM) and the potential to achieve this condition. The study is document-based with exploratory features. The documental corpus consists of the Academic Ranking of World Universities (ARWU), the Times Highter Education Rankings (THE) and the Quacquarelli Symonds World University Ranking (QS), disclosed in the 2011-2015 period; the data provided by the World Wide Web in the yearbooks of UERJ, Unicamp, USP and UNESP; the budget of São Paulo in 2014, data from CAPES (2015), INEP and the websites of the universities. We note that there are three consolidated universities provided UCM (USP, Unicamp and UFRJ) and three in consolidation (UNESP, UFRGS and UFMG). UNESP, UFRGS and the UFRJ have upward trend in the rankings; USP, Unicamp and UFMG have downward trend. It finds potential to reach the UCM condition in 11 universities: PUC-RJ, PUC-RS, UERJ, UFBA, UFPR, UFSC, UFSCar, UTV, UNB, PUC-SP and Unifesp. Brazilian UCM are public, with a mean age of 72 years and with a percentage of 76.49 students in undergraduate and $23.51 \%$ in graduate school. The state of São Paulo has the highest percentage of graduate students and a higher level of investment (annual cost per student). The study found that universities that belong to the World Class have in common publications in journals indexed in databases like SCIE, the SSCI, Thomson Reuters and Scopus.

Key words: University. Rankings criteria. World class.

Este é um artigo publicado em acesso aberto sob uma licença Creative Commons https://creativecommons.org/licenses/by-nc/4.0/ 


\section{Introdução}

As estratégias das universidades europeias, de forma significativa, neste século, são determinadas pela busca de melhores posicionamentos em rankings internacionais, instaurando uma competição global por talentos e deslocando o foco das ações para aspectos mensuráveis (SURSOCK; SMIDT, 2010).

Os rankings universitários mundiais produziram a referência da Universidade de Classe Mundial (UCM) em pesquisa científica. Uma UCM é uma instituição competitiva mundialmente que apresenta maiores probabilidades de receber melhores alunos e professores, de obter investimentos substantivos, de ter a aprovação da comunidade, entre outros benefícios (CALDERÓN; PFISTER; FRANÇA, 2015; SANTOS, 2015).

Estudos envolvendo rankings universitários mundiais, embora recentes, a partir da virada deste século, já são constantes no meio acadêmico.

Ao se utilizar o ranking como instrumento avaliativo em escala mundial, nivela-se universidades de continentes opostos e de realidades diferentes, nivela-se também modos particulares de conceber a finalidade da educação. Esse nivelamento tem recebido críticas de autores como Dias Sobrinho (2004, 2008) e Barreyro (2008). Se de um aspecto os argumentos defendem o uso dos rankings para oferecer informações sobre a instituição auxiliando na facilidade de mobilidade acadêmica, nos critérios de intercâmbio de pesquisadores, na distribuição de fundos públicos e investimentos privados mais fundamentados, na autoanálise institucional; por outro aspecto, realça um lado econômico da educação sem precedentes. Os índices, nesse segundo aspecto, seguem a lógica do mercado, exercem função de controle, de seleção social e de restrição à autonomia institucional.

$\mathrm{O}$ assunto ranking oferece vários aspectos para análise. Há artigos que discutem os critérios adotados pelos rankings (USHER; SAVINO, 2006; ORDORIKA; RODRIGUEZ GOMEZ, 2010; CHEN; LIAO, 2012), outros apresentam universidades que atuam em função dos critérios dos rankings mundiais (POBLETE, 2006; VINCKE, 2012; TAN; GOH, 2014; SCHWEKENDIEK, 2015), há os que analisam os rankings com questionamentos dos critérios e evidenciando os efeitos persuasivos (HUANG, 2012; VALLE, 2006), sugerindo novos critérios para os rankings (BENGOETXEA; BUELA-CASAL, 2013, ROBINSONGARCÍA et al., 2014), questionando os interesses por trás os rankings (DIAS SOBRINHO, 2004; BARREYRO, 2008), entre outros focos. Constata-se, no entanto, que artigos considerando as universidades brasileiras no cenário mundial ainda são incipientes. 
Atualmente, os rankings de maior visibilidade internacional são o Academic Ranking of World Universities (ARWU), Times Highter Education Ranking (THE), Quacquarelli Symonds Wold University Ranking (QS), National Taiwan University Ranking (NTU), Ranking Leiden e Ranking Webometrics. No presente estudo serão examinados os três rankings mundiais mais antigos, o ARWU (2015a, b e c), o THE (2015a, b, e c) e o QS (2015a, b, c e d), entre 2011 e 2015, tendo como escopo as universidades públicas brasileiras.

O estudo objetiva analisar o perfil das universidades brasileiras que estão na condição de Universidade de Classe Mundial (UCM) e as com potencial para atingir essa condição.

O texto, em função dos procedimentos técnicos, caracteriza-se como documental. Trata-se de um estudo de natureza exploratória com abordagem quantitativa. Os dados levantados no corpus documental foram tratados por meio de estatísticas descritivas (medidas de tendência central e medidas de dispersão). As variáveis foram comparadas entre si quanto aos rankings, sendo considerada a média, representatividade e evolução, relacionando ou confrontando as variáveis em cada grupo de informações. Os dados foram submetidos a testes de normalidade de Kolmogorov-Smirnov (KS) e Shapiro-Wilk (SW) para orientar na escolha entre teste paramétrico ou não paramétricos para análise de variância.

\section{Rankings Universitários Mundiais}

A palavra ranking remete a classificação estatística de algo ou alguém, seguindo critérios. Em termos educacionais, a classificação não apenas coloca as universidades numa posição numérica, ela tem uma carga semântica avaliativa de qualidade. As mídias, as universidades e a sociedade agregam a ideia de qualidade superior a instituição com posição mais privilegiada na classificação. Questiona-se de que qualidade se trata? Dias Sobrinho (2008, p.818) afirma que não e expande a indagação: "Mas, que é, mesmo, qualidade? Qual qualidade, quem a define e para quem?”. A crítica ultrapassa o fato de se quantificar a qualidade, atribuindo-lhe um selo, e chega a autonomia universitária, uma vez que a avaliação se limita a controlar, medir, certificar e regular a partir de parâmetros impostos externamente, assim, a comunidade acadêmica fica à margem, pois não há processo participativo e formativo de reflexão nesse modelo de avalição (DIAS SOBRINHO, 2008).

Barreyro (2008) reforça a ideia de que os rankings se aproximam de avalições mercadológicas e afastam-se da avaliação da qualidade, entendida como atribuição de valor e produção de sentido. 
Apesar das críticas à avalição e à classificação, “a avaliação é o principal instrumento para assegurar o êxito e a direção das reformas" (DIAS SOBRINHO, 2004, p. 719) e mesmo sendo corriqueira a visibilidade publicitária oriunda dos rankings, o conhecimento de como são construídos pode atenuar as simplificações midiáticas sobre eles.

\subsection{Academic Ranking of World Universities (ARWU)}

$\mathrm{O}$ ranking Academic Ranking of World Universities (ARWU), confeccionado pela Shanghai Jiao Tong University, é considerado o primeiro ranking universitário mundial. Divulgado desde 2003, o ARWU foi concebido para comparar as condições das universidades chinesas em relação às universidades do restante do mundo. A primeira publicação do ranking produziu tensão, particularmente na Europa, em função de que instituições dos Estados Unidos e do Reino Unido predominaram nas listas das 20 entre as 100 melhores universidades do mundo (NASSI-CALÒ, 2013).

A periodicidade do ARWU é anual. Há a divulgação do Ranking Geral (World top 500 universities), por áreas (ARWU-Field) e por disciplinas (ARWU-Subject). A cada ano são selecionadas aproximadamente 2000 universidades, são classificadas 1200 universidades de cerca de 30 países com critérios objetivos e dados de terceiros (ARWU, 2015a). São divulgados apenas os 500 primeiros nomes de universidades no Ranking Geral, os 200 primeiros nomes no ranking por área (World top 200 universities em Ciências Naturais e Matemática - SCI, Engenharia/Tecnologia e Ciência da Computação - ENG, Ciências da Vida e Ciência Agrária - LIFE, Medicina Clínica e Farmácia - MED e Ciências Sociais - SOC) e 200 por disciplina (World top 200 universities em Matemática, Física, Química, Computador e Economia/Comércio). O ranking por área começou a ser divulgado em 2007 e o por disciplina em 2009.

Os dados para a elaboração do ranking são coletados de instituições independentes (Prêmio Nobel e Medalha Fields), de base de dados da Thomson Reuters e de entidades nacionais, como Ministério da Educação Nacional, Instituto Nacional de Estatísticas, Associação Nacional de Universidades e Colégios e Conferência Nacional do Reitor (ARWU, 2015a, b). Embora o site da ARWU não informe como essas informações são coletadas, percebe-se características subjetivas.

Para a edição de 2015 (ARWU, 2015c), a ARWU considerou seis indicadores distribuídos em quatro categorias: Critérios de qualidade da educação; qualidade da instituição; resultados de pesquisa; desempenho per capto. O quadro 1 apresenta as categorias, o código do indicador e uma breve descrição do indicador e seu peso. 
Quadro 1- Indicadores da ARWU Ranking Geral na edição 2015

\begin{tabular}{|c|c|c|c|c|}
\hline CATEGORIAS & CÓDIGO DO & DESCRIÇÃO & \multicolumn{2}{|c|}{ PESO } \\
\hline $\begin{array}{l}\text { Qualidade da } \\
\text { Educação }\end{array}$ & Alumni & $\begin{array}{l}\text { Número de Prêmios Nobel e Medalhas Fields obtidos } \\
\text { por (ex-)alunos da instituição. Para o cálculo, o peso de } \\
100 \% \text { é dado para os que obtiveram grau de } 2001 \text { a } \\
2010 \text { (de } 2011 \text { até } 2015 \text { não foi considerado); } 90 \% \text { do } \\
\text { peso para àqueles que o grau foi concedido no período } \\
\text { de } 1991 \text { a } 2000 ; 80 \% \text { do peso para os que obtiveram } \\
\text { grau de } 1981 \text { a } 1990 \text {, e assim por diante até chegar em } \\
10 \% \text { para o peso daqueles que obtiveram grau de } 1911 \text { a } \\
\text { 1920. Caso uma pessoa obtenha mais de um grau, } \\
\text { credita-se apenas uma vez para a instituição. }\end{array}$ & $\begin{array}{l}10 \\
\%\end{array}$ & $\begin{array}{l}10 \\
\%\end{array}$ \\
\hline \multirow[t]{2}{*}{$\begin{array}{ll}\text { Qualidade } & \text { da } \\
\text { instituição } & \end{array}$} & Award & $\begin{array}{l}\text { Número total de servidores/funcionários que atuam em } \\
\text { determinada instituição no ano que ganharam Prêmios } \\
\text { Nobel em Física, Química, Medicina ou Economia ou } \\
\text { ainda que ganharam Medalha Fields em matemática. Os } \\
\text { pesos variam de acordo com o período que o prêmio foi } \\
\text { entregue. O peso é de } 100 \% \text { para os vencedores depois } \\
\text { de } 2011 \text {; de } 90 \% \text { para os vencedores entre } 2001 \text { e } 2010 \text {; } \\
80 \% \text { para os vencedores entre } 1991 \text { e } 2000 ; 70 \% \text { para } \\
\text { os vencedores entre } 1981 \text { e } 1990 \text {; e assim por diante até } \\
\text { chegar em } 10 \% \text { para os vencedores entre } 1921 \text { e } 1930 \text {. } \\
\text { Caso um vencedor seja afiliado a mais de uma } \\
\text { instituição, cada instituição recebe uma pontuação (o } \\
\text { site não deixa claro como o percentual é calculado). } \\
\text { Caso um prêmio Nobel seja compartilhado por mais de } \\
\text { uma pessoa, há ajustes nos pesos para os vencedores, } \\
\text { respeitando a proporção do prêmio. }\end{array}$ & $\begin{array}{l}20 \\
\%\end{array}$ & \multirow[t]{2}{*}{$\begin{array}{l}40 \\
\%\end{array}$} \\
\hline & $\mathrm{HiCi}$ & $\begin{array}{l}\text { Pesquisadores altamente citados em } 21 \text { categorias de } \\
\text { assuntos gerais, selecionados por uma lista da Thomson } \\
\text { Reuters. A edição de } 2015 \text { é uma média de duas listas, a } \\
\text { de } 2001 \text {, contando com } 6.000 \text { nomes, usada até } 2013 \text {, e } \\
\text { a nova lista, com metodologia distinta da de } 2001 \text {, } \\
\text { possui } 3.000 \text { nomes. }\end{array}$ & $\begin{array}{l}20 \\
\%\end{array}$ & \\
\hline \multirow[t]{2}{*}{$\begin{array}{l}\text { Resultados de } \\
\text { pesquisa }\end{array}$} & $\mathrm{N} \& \mathrm{~S}$ & $\begin{array}{l}\text { Afere o número de artigos (resultados de pesquisa) } \\
\text { publicados nas revistas Nature e Science nos últimos } 5 \\
\text { anos. Para o cálculo do indicador, é atribuído o peso de } \\
100 \% \text { para o primeiro autor, } 50 \% \text { para o segundo autor, } \\
25 \% \text { para o terceiro autor e } 10 \% \text { para os outros autores. }\end{array}$ & $\begin{array}{l}20 \\
\%\end{array}$ & \multirow[t]{2}{*}{$\begin{array}{l}40 \\
\%\end{array}$} \\
\hline & PUB & $\begin{array}{l}\text { Quantifica o número total de artigos indexados no } \\
\text { Science Citation Index Expanded (SCIE) e no Science } \\
\text { Citation Index Social (SSCI), no ano anterior. No } \\
\text { cálculo dos artigos indexados na base SSCI é atribuído } \\
\text { peso dois. }\end{array}$ & $\begin{array}{l}20 \\
\%\end{array}$ & \\
\hline $\begin{array}{l}\text { Desempenho per } \\
\text { capto }\end{array}$ & PCP & $\begin{array}{l}\text { Ponderação dos cinco indicadores dividido pelo número } \\
\text { de professores de tempo integral. Na ausência do } \\
\text { número de docentes de tempo integral, a ARWU } \\
\text { considera apenas os escores ponderados dos cinco } \\
\text { indicadores. }\end{array}$ & $\begin{array}{l}10 \\
\%\end{array}$ & $\begin{array}{l}10 \\
\%\end{array}$ \\
\hline
\end{tabular}

Fonte: Adaptado de ARWU (2015a, b).

Para fazer parte da lista da ARWU é preciso que a universidade tenha pelo menos uma das seguintes características: ter aluno, ex-aluno ou servidor que recebeu prêmio Nobel Laureates ou Medalha Fields; ter pesquisadores altamente citados; ter artigos publicados na 
Nature ou Science; ter quantidade significativa de artigos indexados pelo Science Citation Index Expanded (SCIE) e pelo Science Citation Index Social (SSCI).

Os critérios de inclusão da ARWU apresentados no sítio disponível na Rede Mundial de Computadores não apresentam parâmetros mensuráveis para definir pesquisadores altamente citados ou quantificar o número mínimo de artigos publicados na Nature ou na Science e também não esclarece o que entende por quantidade significativa de artigos indexados.

O site da ARWU disponibiliza a consulta a todos os rankings divulgados desde $2003 \mathrm{e}$ as estatísticas por região (América, Europa, Ásia/Pacífico, África) e país, disponibilizando os Top 20, Top 100, Top 200, Top 300, Top 400 e o Top 500 das universidades.

Na edição de 2015, o Brasil tem seis universidades no Ranking Top 500: Universidade de São Paulo (USP) (101-150), Universidade Federal do Rio de Janeiro (UFRJ) (301-400), Universidade Estadual de São Paulo (UNESP) (301-400), Universidade de Campinas (Unicamp) (301-400), Universidade Federal de Minas Gerais (UFMG) (401-500) e Universidade Federal do Rio Grande do Sul (UFRGS) (401-500). No Ranking Fields, das cinco áreas, a única que não aparece uma universidade brasileira é a SOC. Nas demais, a USP aparece entre 101-150. O Ranking Subject traz nas listas da Matemática e da Ciência da Computação a USP (76-100 e 151-200) e a Unicamp (151-200 e 101-150); no ranking de Física e Química aparece apenas a USP (151-200) e na disciplina de Economia e Negócios não há representante brasileiro.

A classificação das universidades no Top 500 se dá até a posição 100, após a classificação passa a ser por ordem alfabética em grupos de 50 até a posição 200, segue grupos de 100 até a posição 500. A classificação da Top 200 Field e Subject é feita até a posição 50, após há a classificação por ordem alfabética em grupo de 25 até a posição 100, após em grupo de 50 até a posição 200.

A ARWU surgiu para comparar as universidades chinesas com o resto do mundo, isso faria com que os chineses soubessem para onde enviar seus estudantes e o governo teria parâmetros para estabelecer no país UCMs (SANTOS, 2015). Pelos critérios adotados pela ARWU, percebe-se um elevado padrão de qualidade em pesquisa. São critérios rigorosos para a realidade brasileira. Tem-se uma única Medalha Fields no país, o ganhador é naturalizado francês e não é professor universitário. A participação do Brasil se dá pela atuação nos outros indicadores. Mesmo com uma pontuação máxima de $70 \%$ da nota, o Brasil está no Ranking Geral desde a primeira edição. De 2003 até 2006 com quatro universidades (USP, UFRJ, Unicamp, UNESP), em 2007, com a UFMG, foram cinco, em 2008 somaram seis, com a 
participação da UFRGS. De lá até 2015, o Brasil manteve-se com esses seis nomes na lista, exceção feita em 2011, que atingiu sete nomes, com a UNIFESP.

\subsection{Times Higher Education World University Rankings (THE)}

O Times Higher Education World University Rankings (THE) nasceu como um suplemento do Jornal The Times, divulgando o nome das 200 universidades ranqueadas como as melhores do mundo. De 2004 até 2009 o ranking tinha parceria com a empresa britânica Quacquarelli Symonds (QS). Por conta das críticas, o THE ajustou sua metodologia em 2005, 2007, 2008 e 2009, até desfazer a parceria com a QS, em outubro de 2009, e passar a ter os dados para o ranking fornecido pela Thomson Reuters. Com a parceria desfeita, a QS passou a produzir seu próprio ranking, o QS World University Rankings, e, por deter a propriedade intelectual e metodológica do ranking THE-QS, detém também os rankings desde 2004 (SANTOS, 2015).

Com a parceria da Thomson Reuters, desde 2010, o ranking THE adotou nova metodologia, que permanece inalterada desde a edição 2010-2011, proporcionando uma série histórica. O ranking tem periodicidade anual. Publica, desde 2011, o Ranking Global (THE Wold University Rankings) com o nome das 400 melhores universidades. Na edição 20152016 esse número passou para 800. Também desde 2011 é publicado o Ranking Reputação (World Reputation Rankings), desde 2012, o ranking 100 abaixo dos 50 (100 under 50), que na edição de 2016 passou a ser 150 abaixo dos 50 (150 under 50). Desde 2013 a THE publica o Ranking das Universidades da Ásia (Asia University Rankings), todos com 100 nomes de universidades. Desde 2014, o Ranking BRICS e Economias Emergentes (BRICS \& Emerging Economies Rankings), com 200 nomes na lista (QS, 2015d).

As 800 universidades do Ranking Global também estão classificadas em seis áreas, podendo ser consultadas no Ranking by Subject - Artes e Humanidades; Ciências Clínicas, Pré-clínicas e da Saúde; Engenharia e Tecnologia; Ciências da Vida; Ciências Físicas e Ciências Sociais. É possível a consulta ao desempenho de cada universidade nos cinco critérios de avaliação da THE (ensino; pesquisa; citação; perspectiva internacional; captação de investimentos da indústria) e à estatística em quatro indicadores (número equivalente a estudantes de tempo integral na universidade; proporção entre aluno/equipe acadêmica; percentual de estudantes estrangeiros; proporção entre os sexos feminino e masculino). Os dados da estatística são fornecidos pelas universidades para a THE, e podem se alterar de ano a ano. Os dados do ranking 2015/2016 foram coletados em 2013. 
A edição do Ranking Global 2015-2016 é a primeira, desde 2009, a utilizar citações de periódicos acadêmicos da base Scopus da Elsevier (BOTHWELL, 2015a) e a dobrar o número de universidades divulgadas (BOTHWELL, 2015b).

A THE adota critérios de análise das instituições baseados nas missões fundamentais de uma universidade: ensino, investigação, transferência de conhecimento e perspectiva internacional (THE, 2015a, b).

A metodologia da edição de 2015-2016 do Ranking Global da THE considera treze indicadores distribuídos em cinco categorias (ensino: ambiente de aprendizado; pesquisa: reputação, orçamento e volume; citação: influência da pesquisa; perspectiva internacional; investimento da indústria) (Quadro 2):

Quadro 2 - Indicadores da THE Ranking Global da edição 2015-2016

\begin{tabular}{|c|c|c|c|c|}
\hline CATEGORIA & INDICADOR & DESCRIÇÃO & \multicolumn{2}{|c|}{ PESO } \\
\hline \multirow[t]{5}{*}{$\begin{array}{l}\text { Ensino: } \\
\text { ambiente de } \\
\text { aprendizagem }\end{array}$} & $\begin{array}{l}\text { Reputação } \\
\text { acadêmica }\end{array}$ & $\begin{array}{l}\text { Resultados obtidos por meio de pesquisa de opinião } \\
\text { entre acadêmicos, sobre o prestígio e reputação das } \\
\text { instituições de ensino. Dados coletados em dezembro } \\
\text { de } 2014 \text { e janeiro de } 2015 \text { em variados lugares do } \\
\text { mundo e diversificadas pessoas. }\end{array}$ & $\begin{array}{c}15,0 \\
\%\end{array}$ & \multirow[t]{5}{*}{$\begin{array}{c}30,0 \\
\%\end{array}$} \\
\hline & Doutores & $\begin{array}{l}\text { Relaciona o número de doutorados de uma instituição } \\
\text { com o número total do corpo docente. A relação } \\
\text { justifica-se pela crença de que uma instituição com } \\
\text { muitos doutores esteja preocupada com a nova geração } \\
\text { de acadêmicos e que, o fato de ter muitos doutores, } \\
\text { proporcione um nível mais alto de ensino. }\end{array}$ & $6,0 \%$ & \\
\hline & $\begin{array}{l}\text { Alunos / } \\
\text { equipe } \\
\text { acadêmica }\end{array}$ & $\begin{array}{l}\text { Proporção entre o número de alunos de graduação } \\
\text { admitidos em relação ao número de docentes. Essa } \\
\text { relação supõe que quanto maior o número de alunos, } \\
\text { mais numerosa deve ser a equipe que dará suporte para } \\
\text { o aluno, promovendo ensino de qualidade. A relação é } \\
\text { calculada como um proxy simples (variável para } \\
\text { substituir outra de difícil mensuração). }\end{array}$ & $4,5 \%$ & \\
\hline & Orçamento & $\begin{array}{l}\text { Relação entre o orçamento da instituição e o número } \\
\text { de docentes. É um valor ajustado pela Paridade do } \\
\text { Poder de Compra (PPC). O PPC ajusta o valor que se } \\
\text { obtém da relação do orçamento com o corpo docente } \\
\text { de uma universidade de um determinado país com o } \\
\text { valor obtido por outra universidade de outro país que } \\
\text { tenha moeda diferente; assim todas as nações podem } \\
\text { competir em igualdade de condições. }\end{array}$ & $\begin{array}{c}2,25 \\
\%\end{array}$ & \\
\hline & $\begin{array}{l}\text { Doutores / } \\
\text { bacharel }\end{array}$ & $\begin{array}{l}\text { Proporção entre o número de doutorandos e a de } \\
\text { bacharelados concedidos. O site não fornece detalhes } \\
\text { para saber como o indicador é calculado, sabe-se que a } \\
\text { lógica usada defende que instituições com maior } \\
\text { concentração de estudantes de pesquisa apresentam } \\
\text { mais conhecimento e que uma instituição com uma } \\
\text { comunidade de pós-graduação ativa tem um ambiente } \\
\text { de ensino e de pesquisa mais valorizado por alunos de } \\
\text { graduação e pós-graduação. }\end{array}$ & $\begin{array}{c}2,25 \\
\%\end{array}$ & \\
\hline $\begin{array}{l}\text { Pesquisa: } \\
\text { reputação, } \\
\text { orçamento e }\end{array}$ & $\begin{array}{c}\text { Reputação em } \\
\text { pesquisa }\end{array}$ & $\begin{array}{l}\text { Resultados obtidos por meio da pesquisa de opinião } \\
\text { entre os acadêmicos, sobre o prestígio e reputação das } \\
\text { instituições em pesquisa. }\end{array}$ & $\begin{array}{c}18,0 \\
\%\end{array}$ & $\begin{array}{c}30,0 \\
\%\end{array}$ \\
\hline
\end{tabular}




\begin{tabular}{|c|c|c|c|c|}
\hline \multirow[t]{2}{*}{ volume } & $\begin{array}{l}\text { Investimento } \\
\text { em pesquisa }\end{array}$ & $\begin{array}{l}\text { Relação entre o orçamento destinado à pesquisa e o } \\
\text { número de docentes, os dados são balizados pelo PPC. } \\
\text { Usa-se o PPC para se ter o mesmo parâmetro entre } \\
\text { países e disciplinas ditas "ciências duras" comparadas } \\
\text { com outras (é comum haver valores maiores de bolsa } \\
\text { para aquelas em relação a essas). }\end{array}$ & $6,0 \%$ & \\
\hline & Publicação & $\begin{array}{l}\text { Medida simples de produtividade em pesquisa: a } \\
\text { relação de artigos publicados nos periódicos } \\
\text { acadêmicos indexados pela base de dados Scopus da } \\
\text { Elsevier pelo número de docentes, escalonado para o } \\
\text { tamanho total da universidade e também normalizada } \\
\text { por assunto. Esse procedimento aproxima as condições } \\
\text { de publicação entre universidade. }\end{array}$ & $6,0 \%$ & \\
\hline $\begin{array}{l}\text { Citação: } \\
\text { influência da } \\
\text { pesquisa }\end{array}$ & Citação & $\begin{array}{l}\text { Capta o número de vezes que trabalhos publicados de } \\
\text { uma universidade é citado comparando com o número } \\
\text { de citações que se espera ter de uma publicação de } \\
\text { similar tipo e assunto. A Elsevier examinou mais de } 51 \\
\text { milhões de citações, de } 11,3 \text { milhões de artigos de } \\
\text { revistas, publicados ao longo de cinco anos. Os dados } \\
\text { foram extraídos dos } 23.000 \text { periódicos acadêmicos } \\
\text { indexados pela base de dados Scopus da Elsevier e } \\
\text { incluiu todos os periódicos indexados, publicados } \\
\text { entre } 2010 \text { e } 2014 \text {; também inclui as citações, dos } \\
\text { últimos seis anos (2010-2015), dos três tipos de } \\
\text { publicações consideradas: artigos de periódicos, anais } \\
\text { de conferências e avaliações. Os dados são } \\
\text { normalizados para equiparar o volume de citação entre } \\
\text { diferentes áreas do conhecimento, isso evita que áreas } \\
\text { tradicionalmente de elevada citação não beneficie } \\
\text { instituições. }\end{array}$ & $\begin{array}{c}30,0 \\
\%\end{array}$ & $\begin{array}{c}30,0 \\
\%\end{array}$ \\
\hline \multirow[t]{3}{*}{$\begin{array}{l}\text { Perspectiva } \\
\text { internacional }\end{array}$} & $\begin{array}{l}\text { Estudantes } \\
\text { estrangeiros / } \\
\text { Nacionais }\end{array}$ & $\begin{array}{l}\text { Proporção de estudantes estrangeiros em relação ao } \\
\text { número de estudantes nacionais da instituição. A } \\
\text { relação evidenciará que a capacidade da universidade } \\
\text { em atrair alunos de graduação e pós-graduados de todo } \\
\text { o planeta é um diferencial para seu sucesso no cenário } \\
\text { mundial. }\end{array}$ & $2,5 \%$ & \multirow[t]{3}{*}{$7,5 \%$} \\
\hline & $\begin{array}{l}\text { Docentes } \\
\text { estrangeiros / } \\
\text { Nacionais }\end{array}$ & $\begin{array}{l}\text { Proporção de docentes estrangeiros em relação ao } \\
\text { número de docentes nacionais da instituição. A THE } \\
\text { acredita que tanto maior será o sucesso de uma } \\
\text { instituição mundialmente quanto maior será o número } \\
\text { de intercâmbio de pessoas. }\end{array}$ & $2,5 \%$ & \\
\hline & $\begin{array}{l}\text { Colaboração } \\
\text { internacional }\end{array}$ & $\begin{array}{l}\text { Proporção do total de publicações em revistas de } \\
\text { pesquisa da universidade, nos últimos } 5 \text { anos, com } \\
\text { pelo menos um autor estrangeiro. }\end{array}$ & $2,5 \%$ & \\
\hline $\begin{array}{l}\text { Investimento da } \\
\text { indústria: } \\
\text { inovação }\end{array}$ & $\begin{array}{l}\text { Recursos da } \\
\text { indústria }\end{array}$ & $\begin{array}{l}\text { Medida dos recursos destinados à pesquisa } \\
\text { proveniente da indústria em relação ao número de } \\
\text { acadêmicos. É um indicador que visa captar } \\
\text { "transferência de conhecimento", sugere que uma } \\
\text { instituição tem qualidade se ela consegue atrair } \\
\text { financiamento do mercado privado e se esse valor é } \\
\text { significativo/elevado. }\end{array}$ & $2,5 \%$ & $2,5 \%$ \\
\hline
\end{tabular}

Fonte: Autoria própria (2015).

Os percentuais dos indicadores adotados pelo THE Subject Ranking são diferenciados do Ranking Global, embora os critérios sejam os mesmos. Os critérios de inclusão para uma universidade fazer parte da lista mudam em relação ao Ranking Global. A exigência de 200 
artigos por ano nos últimos cinco anos altera-se para 100 artigos por ano para assuntos que geram um alto volume de publicações e 50 por ano em disciplinas como Ciências Sociais e Artes e Humanidades, onde o volume tende a ser menor (THE, 2015a), além disso, exige-se que $5 \%$ do corpo docente atuem em uma das seis áreas do ranking.

Quanto a metodologia usada nos outros rankings da THE, os indicadores são os mesmos, há, entretanto, sutilezas e alterações nos percentuais comparados com o Ranking Global.

O World Reputation Rankings emprega pesquisa de opinião acadêmica. São convidados peritos considerados de alto nível para indicarem nomes de universidades. O THE Reputation é um ranking de julgamento subjetivo.

O THE 100 Under 50 foi criado para mostrar universidades jovens que apresentam grande potencial. A metodologia empregada contempla os mesmos treze indicadores usados pelo World University Rankings, mas com ajustes nos pesos, recalibrados para refletir as características especiais das universidades mais jovens, desse modo, indicadores de reputação têm menor peso.

O Ásia University Rankings também usa os mesmos treze indicadores de desempenho do World University Rankings com ajustes adequados. Visa fornecer comparações abrangentes e equilibrados, confiáveis a estudantes, acadêmicos, líderes universitários, indústria e governos.

O mesmo procedimento de ajuste metodológico foi usado para o BRICS \& Emerging Economies (QS, 2015d), em que o ajuste é dado para sistemas de investigação menos maduros e para diferentes prioridades de desenvolvimento.

A THE disponibiliza todas as edições do ranking, possibilitando comparativos.

Na edição 2015-2016 do THE Ranking Geral, com a divulgação de 800 universidades (na edição 2014-2015 eram 400), o Brasil passou de duas para 17 universidades ranqueadas (Quadro 3). 
Quadro 3 - Posição das universidades brasileiras no Ranking Geral da THE 2015-2016

\begin{tabular}{|c|c|}
\hline POSIÇÃO & UNIVERSIDADE \\
\hline $251-300$ & USP. \\
\hline $351-400$ & Unicamp. \\
\hline $501-600$ & UFRJ; Pontifícia Universidade Católica do Rio de Janeiro (PUC Rio). \\
\hline $601-800$ & $\begin{array}{c}\text { Universidade de Brasília (UnB); Universidade Federal da Bahia (UFBA); UFMG; } \\
\text { Universidade Federal do Paraná (UFPR); UFRGS; Universidade Federal de Santa Catarina } \\
\text { (UFSC); Universidade Federal de São Carlos (UFSCAR); Universidade Federal de Viçosa } \\
\end{array}$ \\
$\begin{array}{c}\text { (UFV); Universidade Federal de Lavras (UFLA); Pontifícia Universidade Católica do Paraná } \\
\text { (PUC PR); PUC do Rio Grande do Sul (PUC RS); Universidade Estadual do Rio de Janeiro } \\
\text { (UERJ); Universidade do Estado de São Paulo (UNESP). }\end{array}$ \\
\hline
\end{tabular}

Fonte: Adaptado do THE (2015c).

Obs.: O THE classifica a primeira universidade até a posição 200, depois as universidades são apresentadas por ordem alfabética em grupos de 50 até a posição 400, em grupos de 100 até a posição 600 e, por último, em grupos de 200 até a posição 800 .

Na edição 2015/2016 do Ranking by Subject o Brasil não tem universidade na lista. Na edição de 2014/2015 a USP representava o Brasil na posição 79 na área de Ciências Clínicas, Pré-clínicas e da Saúde e na posição 92 em Ciências da Vida. As áreas de Engenharia e Tecnologia; Ciências Físicas; Artes e Humanidades e Ciências Sociais, o Brasil também não tinha universidade na lista.

A edição 2015/2016 do BRICS \& Emerging Economics Rankings tem 14 universidades brasileiras na lista. A USP é a universidade melhor classificada com a $9^{\text {a }}$ posição, seguida da Unicamp (=24), PUC-RJ (43), UFRJ (89), UFV (102), UFMG (=118), UNESP (=122), PUC-RS (=125), UFRGS (=130), UFSC (148), UFSCar (167), PUC-PR (168), UFLA (=185), UERJ (=197). Na edição de 2014/2015 desse mesmo ranking, o Brasil tinha apenas quatro universidades na lista. A USP ocupava a $10^{\mathrm{a}}$ posição, a Unicamp a $27^{\mathrm{a}}$, a UFRJ a $61^{\mathrm{a}}$ e a UNESP a $97^{\mathrm{a}}$.

Na edição 2016 do ranking Reputação a representante é a USP (91-100) e do ranking 150 abaixo de 50 é a Unicamp (61).

Para uma universidade participar do THE é necessário não estar enquadrada nos critérios de exclusão: universidades que não ofereçam graduação, que atuam em câmpus excessivamente especializado e que tenham menos de 1000 artigos publicados entre 2008 e 2012 (200 por ano) (THE, 2015a, b).

A THE tem como característica dados qualitativos (pesquisa de opinião) e quantitativos (indicadores de desempenho). Claramente a educação e a pesquisa são o foco deste ranking. O maior percentual de indicador (30\%) é a citação de base WoS, que fornece dados de citação e volume de produção. Essas características da THE parecem favorecer a representatividade das universidades brasileiras, comparada com a ARWU. Conclusão 
equivocada, pelo menos até 2014. No início da fase independente da THE, em 2010, o Brasil não teve representatividade. De 2011 até 2014 o Brasil teve a USP e a Unicamp como únicas representantes. Para a THE, o reconhecimento da sociedade tem um alto índice na pontuação, e o Brasil, na edição de 2015/2016, cresceu nesse reconhecimento dos pares.

\subsection{Quacquarelli Symonds World University Rankings - QS}

O Quacquarelli Symonds surgiu no mundo dos rankings em 2004. Em 2010 começou a fase independente da THE. A edição do ranking QS é anual, geralmente lançada no mês de setembro.

A QS elabora seis rankings: o Ranking Mundial (QS World University Rankings), o Ranking Mundial por Disciplinas (QS World University Ranking by Subject), o Ranking Mundial por Área (QS World University Ranking by Faculty), o Ranking por Região (QS University Ranking by Region), o Ranking das Melhores Cidades para o Aluno (QS Best Student Cities) e o Ranking 50 Abaixo de 50 (QS Top 50 Under 50).

A edição 2015/2016 do Ranking Mundial (QS, 2015c) analisou cerca de 3000 universidades para divulgar o nome de 800. Os resultados são apresentados em uma tabela de classificação interativa, que podem ser filtrados por região, por país, por área (Artes e Humanidades; Engenharia e Tecnologia; Ciências da vida e Medicina; Ciências Naturais; Ciências Sociais e Gestão) e por cada um dos seis indicadores de desempenho usados pela QS (Reputação acadêmica; reputação entre empregadores; estudante por professor; professores estrangeiros; estudantes estrangeiros; citação por professor).

É divulgada uma lista com 300 nomes de universidades no Ranking Mundial por Área e no Ranking por Região (Ásia, América Latina e BRICS), exceção feita para a Região Árabe, que acontece a divulgação de 100 universidades e a Região EECA (Emerging Europe \& Central), com 150 universidades, 200 nomes no Ranking Mundial por Disciplinas, 100 nomes de universidade com menos de 50 anos e 75 nomes de cidades no ranking das melhores cidades.

O QS Ranking Mundial tem por objetivo principal ajudar os alunos a fazer comparações informadas das principais universidades do mundo. A metodologia avalia as universidades em quatro áreas: pesquisa, ensino, empregabilidade e internacionalização (QS, 2015a, b), considerando seis indicadores (Quadro 4): 
Quadro 4 - Indicadores da QS Ranking Mundial da edição 2015-2016

\begin{tabular}{|c|c|c|c|c|}
\hline CRITÉRIOS & INDICADOR & DESCRIÇÃO & \multicolumn{2}{|c|}{ PESO } \\
\hline \multirow[t]{2}{*}{ Reputação } & $\begin{array}{l}\text { Reputação } \\
\text { Acadêmica }\end{array}$ & $\begin{array}{l}\text { Pontos obtidos pelas instituições na pesquisa de } \\
\text { opinião global, em que os pares acadêmicos } \\
\text { identificam as instituições, excetuando-se a própria, } \\
\text { dentro de sua área, em que acreditam que o melhor } \\
\text { trabalho esteja acontecendo. Para a edição } \\
2015 / 2016 \text { foram compilados um pouco menos de } \\
76.800 \text { respostas, considerando os últimos cinco } \\
\text { anos, entretanto, as respostas mais recentes é que } \\
\text { foram usadas. Para evitar discrepâncias, a QS usa } \\
\text { ponderações regionais. }\end{array}$ & $40 \%$ & \multirow[t]{2}{*}{$50 \%$} \\
\hline & $\begin{array}{l}\text { Reputação } \\
\text { entre } \\
\text { Empregadores }\end{array}$ & $\begin{array}{l}\text { Pontos obtidos pelas instituições na pesquisa de } \\
\text { opinião global, em que os empregadores identificam } \\
\text { as instituições que produzem os melhores } \\
\text { graduados. A edição } 2015 / 2016 \text { obteve mais de } \\
44.200 \text { respostas dos empregadores. }\end{array}$ & $10 \%$ & \\
\hline $\begin{array}{l}\text { Qualidade do } \\
\text { ensino }\end{array}$ & $\begin{array}{l}\text { Estudantes por } \\
\text { Professor }\end{array}$ & $\begin{array}{l}\text { Proporção simples do número de estudantes por } \\
\text { professor da instituição. A ideia é mais professores, } \\
\text { menos alunos por turma, maior supervisão } \\
\text { individual para cada aluno. }\end{array}$ & $20 \%$ & $20 \%$ \\
\hline Impacto & $\begin{array}{l}\text { Citação por } \\
\text { Docente }\end{array}$ & $\begin{array}{l}\text { Total de citações na base Scopus no período de } 5 \\
\text { anos dividido pelo número de docentes da } \\
\text { instituição. }\end{array}$ & $20 \%$ & $20 \%$ \\
\hline \multirow[t]{2}{*}{ Internacionalização } & $\begin{array}{l}\text { Professores } \\
\text { Estrangeiros }\end{array}$ & $\begin{array}{l}\text { Proporção de pesquisadores estrangeiros no corpo } \\
\text { docente da instituição. }\end{array}$ & $5 \%$ & \multirow[t]{2}{*}{$10 \%$} \\
\hline & $\begin{array}{l}\text { Estudantes } \\
\text { Estrangeiros }\end{array}$ & $\begin{array}{l}\text { Proporção de estudantes estrangeiros matriculados } \\
\text { na instituição. }\end{array}$ & $5 \%$ & \\
\hline
\end{tabular}

Fonte: Autoria própria (2015).

Observa-se que metade da nota advém de dados concretos ( 'hard' data) e a outra de questionários globais. O objetivo do indicador Reputação Acadêmica é mostrar a opinião da comunidade acadêmica internacional sobre a credibilidade da instituição. Já o objetivo da Reputação entre Empregadores é mostrar como as universidades são vistas pela empresa, instituições que absorverão os estudantes.

Para Huang (2012), no texto Opening the black box of QS World University, o indicador Reputação deve ser mais questionado pela comunidade acadêmica por razões de problemas na taxa de retorno dos questionários, pela desigualdade dos questionários desenvolvidos, pela presença e ausência de nomes de universidades na lista dos questionários, pela avaliação de algumas universidades apenas por respondentes nacionais, entre outros pontos.

Os indicadores para o Ranking por Região variam sutilmente dos contidos no Ranking Mundial, entretanto, mantém-se os 50\% de dados subjetivos, excetua-se o QS Ásia, onde soma $40 \%$.

Na edição 2015-2016 do QS Ranking Mundial, o Brasil apresenta o mesmo número da edição 2014-2015, 22 universidades (Quadro 5). 
Quadro 5 - Posição das universidades brasileiras no QS Ranking Mundial, edição 2015-2016

\begin{tabular}{|c|c|}
\hline POSIÇÃO & UNIVERSIDADE \\
\hline 143 & USP \\
\hline 195 & Unicamp \\
\hline 323 & UFRJ \\
\hline $451-460$ & UFRGS \\
\hline $481-490$ & UNESP \\
\hline $491-500$ & UnB; Universidade Federal do Estado de São Paulo (UNIFESP) \\
\hline $501-550$ & PUCSP; PUCRJ \\
\hline $551-600$ & UFMG \\
\hline $651-700$ & UERJ; UFSCAR \\
\hline $701+$ & PUCRS; Universidade Estadual de Londrina (UEL); UFBA; UFSC; UFSM; UFV; UFC; \\
& UFPR; UFPE; Universidade Federal Fluminense (UFF) \\
\hline
\end{tabular}

Fonte: Adaptado de QS (2015c).

Obs.: A classificação do QS Ranking Mundial acontece até a posição 400, depois as universidades são apresentadas por ordem alfabética em grupos de dez até a posição 500, em grupos de 50 até a posição 700 e, por fim, é usado o código 701+ até a posição 800.

As universidades brasileiras aparecem nas 36 disciplinas do Ranking Mundial por Disciplinas, em algumas delas entre as 50 melhores do mundo. Destaque para a USP, classificada nas 36 disciplinas. Outras presenças destacadas são: Unicamp classificada em 26 disciplinas, UFRJ em 25, UFMG em 19, UFRGS em 18, PUC-RJ e UNESP em 11, UFSCar em oito e UnB e UFSC em sete. Entre as 50 melhores do mundo aparecem: USP em oito disciplinas, Unicamp em três, UNESP em duas e UFRJ em uma.

A presença de universidades brasileiras no Ranking Mundial por Áreas acontece em quatro das cinco áreas avaliadas. A exceção é a área de Ciências Sociais e Administração. Os destaques são USP, Unicamp, UFRJ e UFMG presentes em quatro áreas e UFRGS em três. Entre as 100 primeiras classificadas, a USP, em três áreas, é a única universidade brasileira ranqueada.

No QS Ranking por Região América Latina são considerados 20 países. O Brasil têm 89 universidades no ranking na edição 2016, o mesmo número da edição 2014/2015. No Quadro 6 são apresentadas as universidades classificadas até a posição 100.

Quadro 6 - Classificação das universidades brasileiras no QS Ranking por Região América Latina, edição 2016

\begin{tabular}{|c|c|}
\hline POSIÇ̃̃O & UNIVERSIDADE \\
\hline 1 & USP \\
\hline 2 & Unicamp \\
\hline 5 & UFRJ \\
\hline 9 & UnB \\
\hline $12-20$ & UNESP, UFMG; PUC-RJ, UFRGS \\
\hline $21-30$ & UFSC, UNIFESP, UFSCar \\
\hline $31-40$ & UFPR, PUC-SP \\
\hline $41-50$ & PUC-RS; UFPE, UERJ, UFF \\
\hline $51-100$ & UFBA, UEL, Universidade Federal do Ceará (UFC), UFV, PUC-Campinas, \\
\hline
\end{tabular}


Fonte: Adaptado de QS (2016).

Obs.: Para fins de apresentação foram agrupadas as universidades classificadas entre 51-100 e omitidas as universidades colocadas em 101 até 300+.

No QS Ranking por Região BRICS, o Brasil apresenta 40 universidades inseridas na última edição do ranking. As universidades classificadas até a posição 100 são apresentadas no Quadro 7.

Quadro 7 - Classificação das universidades brasileiras no QS Ranking por Região BRICS, edição 2014/2015

\begin{tabular}{|c|c|}
\hline POSIÇÃO & UNIVERSIDADE \\
\hline 9 & USP \\
\hline 12 & Unicamp \\
\hline 25 & UFRJ \\
\hline 27 & UNESP \\
\hline 37 & UNIFESP \\
\hline 41 & UFMG \\
\hline 42 & UFRGS \\
\hline 47 & PUCSP; PUCRJ \\
\hline $51-100$ & UnB; UFSC; UFPR; UFPE; UFF; UERJ; PUC-RS; UFV \\
\hline
\end{tabular}

Fonte: Adaptado de QS (2015d).

Obs.: Para fins de apresentação foram agrupadas as universidades classificadas entre 51-100 e omitidas as universidades colocadas em 101 e 200.

Na edição 2016 do Ranking das Melhores Cidades para o Aluno, o Brasil tem a cidade de São Paulo como representante, em 63 lugar. Na edição 2015, o Brasil não tinha representante. Da edição 2015 para a 2016 houve um aumento de 25 nomes de cidades na lista, de 50 nomes passou para 75.

Na edição 2015 do QS Ranking 50 Abaixo de 50, a Unicamp ocupa a 11ª posição e a UNESP está entre a $71^{\mathrm{a}}-80^{\mathrm{a}}$ posição. Na edição de 2014, a Unicamp era a única representante nacional, ocupando a $15^{\text {a }}$ posição. Da edição de 2014 para a de 2015, o QS Top 50 Under 50 duplicou o número de universidades da lista, de 50 nomes passou para 100.

Para fazer parte do banco da QS, há quatro possibilidades de seleção: a universidade precisa pertencer a rankings nacionais, ser mencionada em pesquisa de opinião (Reputação Acadêmica e Reputação entre Empregadores), constar na lista de instituição do país ou região de sua sede, passar na análise da equipe da QS, se solicitou sua inclusão para avaliação, nesse caso, a universidade é analisada segundo alguns critérios e desempenhos de alguns indicadores comparados com o desempenho de outras universidades já constantes na lista (QS, 2015a). 
O ranking QS combina critérios objetivos (Indicadores de Desempenho) com subjetivos (Pesquisa de Opinião), apresentando para a sociedade universidades que se preocupam com o estudo e com o mercado de trabalho, uma vez que é considerada a opinião do empregador na pontuação, avaliando profissionais qualificados para atuarem após a universidade.

A QS, por ter critérios mais amplos de inserção no ranking, como desempenho das universidades em rankings nacionais, balanceamento geográfico e a inscrição pela própria universidade, pode oferecer uma variedade de nomes de universidades mais diversificados que os que constam nas listas dos rankings ARWU e THE. Além disso, com 50\% dos indicadores sendo de fonte subjetiva, vindas da opinião dos entrevistados, pode-se pensar que há maiores chances de universidades brasileiras estarem na lista. Outra modificação que contribui para aumentar as possibilidades de universidades nacionais na lista da QS World University Rankings é o número de universidades na lista. Nos últimos cinco anos a QS passou de 500 nomes (2010, 2011), para 700 em 2012 e, desde 2013, vem divulgando 800 nomes.

Na fase THE-QS, os indicadores eram diferentes dos da fase independente da QS, mas a participação das universidades brasileiras já se mostrou crescente. Em 2004, nenhuma representatividade do Brasil, em 2005 e 2006, a USP representou o país. Em 2007 foram duas universidades, USP e Unicamp. Em 2008 e 2009, foram três universidades, a UFRJ entrou no ranking. Na fase independente da QS, em 2010, o Brasil tinha três universidades (USP, Unicamp, UFRJ) no Ranking Geral QS, em 2011, passou para quatro, com a chegada da UNIFESP a lista. Em 2012, com a ampliação da lista, o Brasil triplica a representatividade, são 12 universidades na lista QS, de 2013 até 2015 a lista se mantém com 22 universidades brasileiras.

\section{Universidades Brasileiras de Classe Mundial}

Para a escritura deste texto, considerou-se universidade brasileira de Classe Mundial as universidades brasileiras classificadas no Ranking Geral da ARWU, no Ranking Global da THE e no Ranking Mundial da QS. O critério de inclusão foi a inserção nos três rankings. As universidades foram pontuadas considerando sua classificação ( $1^{\circ}$ lugar - 1; [... $500^{\circ}$ lugar 500). Para classificações em bloco, utilizou-se o valor médio (por exemplo - 101-150 125,5). Após, foi feita a média das três pontuações para classificar as universidades. A classificação, adaptando procedimento adotado pelo ranking ARWU, aconteceu em: Top 20, 
Top 100, Top 200, Top 300, Top 400, Top 500 e Top 500+. Foram classificadas como UCMs as classificadas até Top 500. As universidades alocadas em Top 500+ foram classificadas como em consolidação.

Ao se mencionar que uma universidade brasileira tem potencial para atingir a condição de Universidade de Classe Mundial, o texto considerou as universidades brasileiras classificadas no Ranking Geral da ARWU, no Ranking Global da THE e no Ranking Mundial da QS. O critério de inclusão foi a inserção em pelo menos dois rankings ou inserção em um ranking até a posição 500. As universidades já classificadas como UCM foram excluídas.

Com os critérios propostos no presente estudo, tem-se que uma universidade é de Classe Mundial quando aparece nos três principais rankings internacionais (no geral). As universidades brasileiras que atendem esse critério são apresentadas no Quadro 8:

Quadro 8 - Universidades brasileiras de Classe Mundial

\begin{tabular}{|c|c|c|}
\hline CLASSIFICAÇÃO & POSIÇÃO RELATIVA & UNIVERSIDADE \\
\hline Top 20 & - & - \\
\hline Top 100 & - & - \\
\hline Top 200 & 181,33 & USP. \\
\hline Top 300 & - & Unicamp. \\
\hline Top 400 & 307,00 & UFRJ. \\
\hline Top 500 & 408,00 & UNESP. \\
\hline Top 500+ & 512,17 & UFRGS. \\
& 535,50 & UFMG. \\
\hline
\end{tabular}

Fonte: Autoria própria (2016).

Pautado ainda na classificação proposta, têm-se no Brasil três universidades consolidadas (USP, Unicamp e UFRJ) e três em consolidação (UNESP, UFRGS e UFMG). É importante destacar que nenhuma universidade brasileira está classificada nos rankings ARWU, THE e QS entre as 100 melhores do mundo. A USP, com a posição relativa 181,33 no ranking geral, é a única universidade que aparece entre as 100 melhores do mundo nos rankings por área: nas cinco áreas avaliadas no QS edição 2016 (Artes e Humanidades; Engenharia e Tecnologia; Ciências da Vida e Medicina; Ciências Sociais e Negócios e em Ciências Naturais), no THE, na edição 2014-2015 em duas áreas (Ciências da Vida; Ciências Clínicas, Pré-clínicas e de Saúde), não aparecendo na edição 2015-2016; no ARWU, das cinco áreas avaliadas, mesmo não estando entre as 100 melhores, aparece entre 101-150 em quatro áreas (Ciências Naturais e Matemática; Engenharia/Tecnologia e Ciências da Computação; Ciências da Vida e Ciência Agrária; Medicina Clínica e Farmácia).

Considerando as universidades brasileiras de Classe Mundial, procurou-se identificar a movimentação das mesmas nesses rankings num período de cinco anos (Quadro 9). 
Quadro 9 - Classificação das universidades brasileiras de Classe Mundial nos rankings ARWU, THE e QS no período de 2011-2015

\begin{tabular}{|c|c|c|c|c|c|c|c|c|c|c|c|c|c|c|c|}
\hline & \multicolumn{5}{|c|}{ ARWU } & \multicolumn{5}{|c|}{ THE } & \multicolumn{5}{|c|}{ QS } \\
\hline \multirow{4}{*}{ IES } & 2 & 2 & 2 & 2 & 2 & 2 & 2 & 2 & 2 & 2 & 2 & 2 & 2 & 2 & 2 \\
\hline & 0 & 0 & 0 & 0 & $\mathbf{0}$ & 0 & 0 & 0 & 0 & 0 & 0 & 0 & 0 & 0 & 0 \\
\hline & $\mathbf{1}$ & 1 & 1 & 1 & 1 & 1 & 1 & 1 & 1 & $\mathbf{1}$ & 1 & 1 & 1 & 1 & 1 \\
\hline & 1 & 2 & 3 & 4 & 5 & 1 & 2 & 3 & 4 & 5 & 1 & 2 & 3 & 4 & 5 \\
\hline \multirow[t]{2}{*}{ USP } & 102 & 101 & 101 & 101 & 101 & \multirow[t]{2}{*}{178} & \multirow[t]{2}{*}{158} & 226 & 201 & 251 & \multirow[t]{2}{*}{169} & \multirow[t]{2}{*}{139} & \multirow[t]{2}{*}{127} & \multirow[t]{2}{*}{132} & \multirow[t]{2}{*}{143} \\
\hline & 150 & 150 & 150 & 150 & 150 & & & 250 & 225 & 300 & & & & & \\
\hline \multirow[t]{2}{*}{ UNICAMP } & 201 & 201 & 301 & 301 & 301 & 276 & 251 & 301 & 301 & 351 & \multirow[t]{2}{*}{235} & \multirow[t]{2}{*}{228} & \multirow[t]{2}{*}{215} & \multirow[t]{2}{*}{206} & \multirow[t]{2}{*}{195} \\
\hline & 300 & 300 & 400 & 400 & 400 & 300 & 275 & 350 & 350 & 400 & & & & & \\
\hline \multirow[t]{2}{*}{ UFRJ } & 301 & 301 & 301 & 301 & 301 & \multirow[t]{2}{*}{-} & \multirow[t]{2}{*}{-} & \multirow[t]{2}{*}{-} & \multirow[t]{2}{*}{-} & 501 & \multirow[t]{2}{*}{381} & \multirow[t]{2}{*}{333} & \multirow[t]{2}{*}{284} & \multirow[t]{2}{*}{271} & \multirow[t]{2}{*}{323} \\
\hline & 400 & 400 & 400 & 400 & 400 & & & & & 600 & & & & & \\
\hline \multirow[t]{2}{*}{ UNESP } & 301 & 301 & 301 & 301 & 301 & \multirow[t]{2}{*}{-} & \multirow[t]{2}{*}{-} & \multirow[t]{2}{*}{-} & \multirow[t]{2}{*}{-} & 601 & - & 551 & 491 & 421 & 481 \\
\hline & 400 & 400 & 400 & 400 & 400 & & & & & 800 & & 600 & 500 & 430 & 490 \\
\hline UFRGS & 401 & 401 & 401 & 401 & 401 & - & - & - & - & 601 & - & 501 & 501 & 471 & 451 \\
\hline & 500 & 500 & 500 & 500 & 500 & & & & & 800 & & 550 & 550 & 480 & 460 \\
\hline UFMG & 301 & 301 & 301 & 301 & 401 & - & - & - & - & 601 & - & 451 & 481 & 451 & 551 \\
\hline & 400 & 400 & 400 & 400 & 500 & & & & & 800 & & 500 & 490 & 460 & 600 \\
\hline
\end{tabular}

Fonte: Autoria própria (2015).

Percebe-se que no ARWU, as seis universidades consideradas estão presentes no período delimitado. No THE, o mais exigente dos rankings, apenas a USP e a Unicamp faziam parte desde 2011. A inserção da UFRJ, UNESP, UFRGS e UFMG aconteceu com a ampliação do número de universidades ranqueadas, estando todas situadas além da posição 500, que era o limite anterior. Quadro similar é encontrado no QS. Apenas a USP, a Unicamp e a UFRJ aparecem desde 2011. Com a ampliação do número de universidades inseridas no ranking em 2012, a UNESP, a UFRGS e a UFMG aparecem e permanecem em todas as edições subsequentes. A principal diferença com o resultado do THE é que a UNESP (em 2013, 2014 e 2015), a UFRGS (em 2014 e 2015) e a UFMG (em 2012, 2013 e 2014) aparecem entre as 500. Considerando o período 2011-2015, tem-se a posição inicial e atual das universidades brasileiras de Classe Mundial e a tendência das mesmas (Quadro 10):

Quadro 10 - Posição relativa das universidades brasileiras de Classe Mundial nos rankings ARWU, THE e QS em 2011 e 2015 e tendência

\begin{tabular}{|c|c|c|c|}
\hline UNIVERSIDADE & $\begin{array}{c}\text { POSIÇÃO RELATIVA INICIAL } \\
(\mathbf{2 0 1 1})\end{array}$ & $\begin{array}{c}\text { POSIÇão RELATIVA ATUAL } \\
\mathbf{( 2 0 1 5 )}\end{array}$ & TENDÊNCIA \\
\hline USP & 157,67 & 181,33 & $\mathrm{~T}-(-23,66)$ \\
\hline UNICAMP & 257,83 & 307,00 & $\mathrm{~T}-(-49,70)$ \\
\hline UFRJ & 427,33 & 408,00 & $\mathrm{~T}+(19,33)$ \\
\hline UNESP & 542,17 & 512,17 & $\mathrm{~T}+(30,00)$ \\
\hline UFRGS & 558,83 & 535,50 & $\mathrm{~T}+(23,33)$ \\
\hline UFMG & 508,83 & 575,50 & $\mathrm{~T}-(-66,67)$ \\
\hline
\end{tabular}

Fonte: Autoria própria (2015).

Ainda que a perda de posições não indique necessariamente diminuição da qualidade, em função de que a classificação depende das demais universidades avaliadas, é notório um 
decréscimo importante das duas principais universidades brasileiras, principalmente na Unicamp. A tendência negativa mais acentuada entre as seis universidades é a da UFMG. A UNESP, a UFRGS e a UFRJ apresentam tendência positiva. Mantida a tendência, UNESP e UFRGS alcançarão, nos próximos cinco anos, a consolidação de UCM.

Seguindo o objetivo proposto, foi constituído um segundo grupo de universidades, o das universidades com potencial para se tornarem de Classe Mundial. Ao se referir a tendência das universidades brasileiras de Classe Mundial, considerou a posição das universidades brasileiras de Classe Mundial no Ranking Geral da ARWU, no Ranking Global da THE e no Ranking Mundial da QS nos anos de 2011 e 2015. Nos casos em que uma universidade não apresentava resultado em 2011, foram adotados os seguintes critérios: (i) considerar o resultado mais antigo; (ii) repetir o resultado de 2015. As universidades foram pontuadas da mesma maneira que na variável Universidades de Classe Mundial brasileiras. Foi estabelecida a posição relativa das universidades em 2011 e 2015 através da média dos três rankings. O resultado de 2011 foi subtraído do resultado de 2015 para obter a variação média no período. Resultados positivos foram classificados como tendência positiva $(\mathrm{T}+)$; igual a zero como tendência neutra (TN); negativos com tendência negativa (T-). Nesse grupo foram incluídas 11 universidades: PUC-RJ; PUC-RS; UERJ; UFBA; UFPR; UFSC; UFSCar; UFV; UnB, PUC-SP; Unifesp (Quadro11). 
Quadro 11 - Classificação das universidades brasileiras acima da 500ª posição nos rankings ARWU, THE e QS no período de 2011-2015

\begin{tabular}{|c|c|c|c|c|c|c|c|c|c|c|c|c|c|c|c|}
\hline \multirow[b]{2}{*}{ IES } & \multicolumn{5}{|c|}{ ARWU } & \multicolumn{5}{|c|}{ THE } & \multicolumn{5}{|c|}{ QS } \\
\hline & $\begin{array}{l}\mathbf{2} \\
\mathbf{0} \\
\mathbf{1} \\
\mathbf{1}\end{array}$ & $\begin{array}{l}2 \\
0 \\
1 \\
2\end{array}$ & $\begin{array}{l}2 \\
\mathbf{0} \\
\mathbf{1} \\
\mathbf{3}\end{array}$ & $\begin{array}{l}2 \\
0 \\
1 \\
4\end{array}$ & $\begin{array}{l}2 \\
0 \\
1 \\
5\end{array}$ & $\begin{array}{l}\mathbf{2} \\
\mathbf{0} \\
\mathbf{1} \\
\mathbf{1}\end{array}$ & $\begin{array}{l}2 \\
0 \\
1 \\
2\end{array}$ & $\begin{array}{l}2 \\
0 \\
1 \\
3\end{array}$ & $\begin{array}{l}2 \\
0 \\
1 \\
4\end{array}$ & $\begin{array}{l}\mathbf{2} \\
0 \\
1 \\
5\end{array}$ & $\begin{array}{l}2 \\
0 \\
1 \\
1\end{array}$ & $\begin{array}{l}2 \\
0 \\
1 \\
2\end{array}$ & $\begin{array}{l}\mathbf{2} \\
\mathbf{0} \\
\mathbf{1} \\
\mathbf{3}\end{array}$ & $\begin{array}{l}2 \\
0 \\
1 \\
4\end{array}$ & $\begin{array}{l}2 \\
0 \\
1 \\
5\end{array}$ \\
\hline PUC-RJ & - & - & - & - & - & - & - & - & - & $\begin{array}{l}501 \\
600 \\
\end{array}$ & - & $\begin{array}{l}551 \\
600 \\
\end{array}$ & $\begin{array}{l}551 \\
600 \\
\end{array}$ & $\begin{array}{l}501 \\
550 \\
\end{array}$ & $\begin{array}{l}501 \\
550 \\
\end{array}$ \\
\hline PUC-RS & - & - & - & - & - & - & - & - & - & $\begin{array}{l}601 \\
800\end{array}$ & - & - & $\begin{array}{l}651 \\
700\end{array}$ & $\begin{array}{l}651 \\
700\end{array}$ & $701+$ \\
\hline UERJ & - & - & - & - & - & - & - & - & - & $\begin{array}{l}601 \\
800\end{array}$ & - & - & $701+$ & $701+$ & $\begin{array}{l}651 \\
700\end{array}$ \\
\hline UFBA & - & - & - & - & - & - & - & - & - & $\begin{array}{l}601 \\
800 \\
\end{array}$ & - & - & $\begin{array}{l}601 \\
650 \\
\end{array}$ & $\begin{array}{l}601 \\
650 \\
\end{array}$ & $701+$ \\
\hline UFPR & - & - & - & - & - & - & - & - & - & $\begin{array}{l}601 \\
800 \\
\end{array}$ & - & - & $\begin{array}{l}651 \\
700\end{array}$ & $\begin{array}{l}651 \\
700\end{array}$ & $701+$ \\
\hline UFSC & - & - & - & - & - & - & - & - & - & $\begin{array}{l}601 \\
800\end{array}$ & - & $\begin{array}{c}601 \\
+\end{array}$ & $\begin{array}{l}651 \\
700\end{array}$ & $\begin{array}{l}651 \\
700\end{array}$ & $701+$ \\
\hline UFCar & - & - & - & - & - & - & - & - & - & $\begin{array}{l}601 \\
800 \\
\end{array}$ & - & $\begin{array}{c}601 \\
+ \\
\end{array}$ & $\begin{array}{l}601 \\
650 \\
\end{array}$ & $\begin{array}{l}551 \\
600 \\
\end{array}$ & $\begin{array}{l}651 \\
700 \\
\end{array}$ \\
\hline UFV & - & - & - & - & - & - & - & - & - & $\begin{array}{l}601 \\
800 \\
\end{array}$ & - & - & $\begin{array}{l}601 \\
650 \\
\end{array}$ & $701+$ & $701+$ \\
\hline UnB & - & - & - & - & - & - & - & - & - & $\begin{array}{l}601 \\
800 \\
\end{array}$ & - & $\begin{array}{l}551 \\
600 \\
\end{array}$ & $\begin{array}{l}551 \\
600 \\
\end{array}$ & $\begin{array}{l}551 \\
600 \\
\end{array}$ & $\begin{array}{l}491 \\
500 \\
\end{array}$ \\
\hline PUC-SP & - & - & - & - & - & - & - & - & - & - & - & $\begin{array}{l}551 \\
600 \\
\end{array}$ & $\begin{array}{l}551 \\
600 \\
\end{array}$ & $\begin{array}{l}551 \\
600 \\
\end{array}$ & $\begin{array}{l}501 \\
550 \\
\end{array}$ \\
\hline Unifesp & $\begin{array}{l}401 \\
500 \\
\end{array}$ & - & - & - & - & - & - & - & - & - & $\begin{array}{l}401 \\
500\end{array}$ & $\begin{array}{l}401 \\
500 \\
\end{array}$ & $\begin{array}{l}411 \\
420\end{array}$ & $\begin{array}{l}421 \\
430 \\
\end{array}$ & $\begin{array}{l}491 \\
500 \\
\end{array}$ \\
\hline
\end{tabular}

Fonte: Autoria própria (2016).

No Quadro 12 é apresentada a natureza jurídica das universidades que compõe os grupos UCM e universidade com potencial para se tornar de Classe Mundial.

Considerando o art. 19 da Lei $n^{\circ}$ 9.394/1996, as universidades selecionadas foram classificadas em: públicas (criadas ou incorporadas, mantidas e administradas pelo Poder Público) e privadas (mantidas e administradas por pessoas físicas ou jurídicas de direito privado). As instituições públicas foram classificadas, considerando o mantenedor, em: federal, estadual (incluindo o Distrito Federal) e municipal. As instituições privadas em: particulares em sentido estrito (instituídas e mantidas por uma ou mais pessoas físicas ou jurídicas de direito privado que não apresentem as características das demais instituições privadas); comunitárias (instituídas por grupos de pessoas físicas ou por uma ou mais pessoas jurídicas, inclusive cooperativas de professores e alunos que incluam na sua entidade mantenedora representantes da comunidade); confessionais (instituídas por grupos de pessoas físicas ou por uma ou mais pessoas jurídicas que atendem a orientação confessional e ideologia específicas e atendam o exigido para as comunitárias); filantrópicas (na forma da lei).

O grupo UCM, na coluna Condição, é apresentado subdividido em consolidado e em consolidação. 
Quadro 12 - Natureza jurídica das universidades brasileiras de Classe Mundial e com potencial para se tornarem de Classe Mundial

\begin{tabular}{|c|c|c|}
\hline CONDIÇÃO & UNIVERSIDADE & NATUREZA JURÍDICA \\
\hline \multirow{3}{*}{$\begin{array}{l}\text { Universidade de Classe Mundial } \\
\text { consolidada }\end{array}$} & USP & Pública, Estadual (São Paulo) \\
\hline & Unicamp & Pública, Estadual (São Paulo) \\
\hline & UFRJ & Pública, Federal \\
\hline \multirow{3}{*}{$\begin{array}{l}\text { Universidade de Classe Mundial em } \\
\text { consolidação }\end{array}$} & UNESP & Pública, Estadual (São Paulo) \\
\hline & UFRGS & Pública, Federal \\
\hline & UFMG & Pública, Federal \\
\hline \multirow[t]{11}{*}{$\begin{array}{l}\text { Universidade com potencial para se } \\
\text { tornar de Classe Mundial }\end{array}$} & PUC-RJ & $\begin{array}{c}\text { Privada, Confessional / } \\
\text { Filantrópica }\end{array}$ \\
\hline & PUC-RS & $\begin{array}{c}\text { Privada, Confessional / } \\
\text { Filantrópica }\end{array}$ \\
\hline & UERJ & Pública, Estadual (Rio de Janeiro) \\
\hline & UFBA & Pública, Federal \\
\hline & UFPR & Pública, Federal \\
\hline & UFSC & Pública, Federal \\
\hline & UFSCar & Pública, Federal \\
\hline & UFV & Pública, Federal \\
\hline & UnB & Pública, Federal \\
\hline & PUC-SP & $\begin{array}{c}\text { Privada, Confessional / } \\
\text { Filantrópica }\end{array}$ \\
\hline & Unifesp & Pública, Federal \\
\hline
\end{tabular}

Fonte: Autoria própria (2015).

Constata-se que a maioria $(\mathrm{n}=14 ; 82,35 \%)$ das 17 universidades é pública. Das públicas, 10 são federais $(71,43 \%)$ e quatro estaduais $(28,57 \%)$, três localizadas no Estado de São Paulo e uma no Rio de Janeiro. Todas as UCMs (n=6; 100\%) são públicas. Entre as consolidadas, as duas estaduais de São Paulo $(66,67 \%)$ ocupam as duas primeiras posições. Nas em consolidação, encontram-se duas federais $(66,67 \%)$ e uma estadual paulista $(33,33 \%)$. Nas universidades com potencial para se tornarem de Classe Mundial, oito públicas (72,73\%), sendo sete federais e uma estadual do Rio de Janeiro, e três privadas $(27,27 \%)$, todas da PUC.

A relação entre o ano de fundação da universidade e o potencial da universidade para se tornar instituição de Classe Mundial é o foco do próximo quadro (Quadro 13). Considerouse o ano em que as universidades estudadas foram fundadas, classificadas com referência ao ano de 2015, em quatro grupos: mais de 100 anos; entre 76 e 100 anos; entre 51 e 75 anos; menos de 50 anos. 


\section{Quadro 13 - Ano de criação das universidades brasileiras de Classe Mundial e com potencial para se tornarem de Classe Mundial}

\begin{tabular}{|c|c|}
\hline $\begin{array}{c}\text { EXISTÊNCIA (EM } \\
\text { ANOS) }\end{array}$ & UNIVERSIDADE \\
\hline Mais de 100 anos & UFPR (1912). \\
\hline Entre 76 e 100 anos & UFRJ (1920); UFV (1922); UFMG (1927); Unifesp (1933); USP (1934); UFRGS \\
& (1934); PUC-RJ (1940) \\
\hline Entre 51 e 75 anos & PUC-SP (1946); UFBA (1946); PUC-RS (1948); UERJ (1950); UFSC (1960); \\
& UnB (1962). \\
\hline Menos de 50 anos & UNICAMP (1966); UFSCar (1968); UNESP (1976). \\
\hline
\end{tabular}

Fonte: Sítios das universidades na rede mundial de computadores (2015).

A média do tempo de existência das UCMs é de 72,17 $(\mathrm{dp}=22,65)$ anos, enquanto das universidades com potencial para se tornarem de Classe Mundial é de 67,50 (dp=13,80) anos. Os dois grupos foram submetidos e aprovados nos testes de normalidade de KS e SW ( $p>0,10)$. Em seguida foram submetidos a análise de variância, através do teste $T$, com correção de Welch por não apresentam desvios padrões não equivalentes. E verificou-se inexistência de diferenças significativas entre as médias dos grupos ( $\mathrm{p}=0,6619 ; \mathrm{p}>0,05)$, o que sugeri que o tempo de existência não é determinante para categorizar os grupos. Duas universidades do Estado de São Paulo (Unicamp e UNESP) reduziram a média do tempo de existência e aumentaram o desvio padrão no grupo UCM. Unicamp e UNESP possuem menos de 50 anos de história. Merece menção que, no QS ranking 50 abaixo de 50, a UNICAMP ocupa a décima primeira posição, o que a coloca como uma das mais importantes universidades jovens do mundo. Em outros termos, apesar desses grupos comportarem algumas das universidades mais antigas do Brasil, incluindo a UFRJ que pode ser considerada a mais antiga formalizada (CUNHA, 1980), tem-se um conjunto de universidades ainda muito jovens. As universidades mais tradicionais do mundo bem mais que um século. Dessas, algumas são milenares.

Na Quadro 14 é apresentado o quantitativo de alunos de graduação, de pós-graduação e o total de alunos das universidades estudadas, bem como os respectivos percentuais.

Considerou-se o número de alunos de graduação e de pós-graduação no ano de 2014 e os respectivos percentuais no total. Os alunos do Ensino a Distância (EaD) não foram computados. Apresentou-se apenas as universidades públicas, escopo do presente estudo. As universidades públicas representam a totalidades das UCMs brasileiras e a maioria, considerando também as universidades com potencial para atingirem a Classe Mundial ( $\mathrm{n}=$ $14 ; 82,35 \%)$. 
Quadro 14 - Número e percentual de alunos de graduação e de pós-graduação das universidades brasileiras de Classe Mundial e com potencial para se tornarem de Classe Mundial em 2014

\begin{tabular}{|c|c|c|c|}
\hline \multirow{2}{*}{ UNIVERSIDADE } & $\begin{array}{c}\text { GRADUAÇÃO } \\
\text { (PERCENTUAL DO } \\
\text { TOTAL) }\end{array}$ & $\begin{array}{c}\text { PÓS-GRADUAÇÃO } \\
\text { (M+D+MP) } \\
\text { (PERCENTUAL DO } \\
\text { TOTAL) }\end{array}$ & TOTAL \\
\hline USP & $\begin{array}{c}59.081(71,58 \%)^{1} \\
(28,42 \%)^{6}\end{array}$ & $\begin{array}{c}23.455(9.959+13.028+468) \\
82.536\end{array}$ \\
\hline Unicamp & $18.698(68,96 \%)^{2}$ & $8.416(3.341+4.943+132)(31,04 \%)^{6}$ & 27.114 \\
\hline UFRJ & $39.887(80,26 \%)^{3}$ & $9.811(4.049+5.011+751)(19,74 \%)^{6}$ & 49.698 \\
\hline UNESP & $37.388(80,53 \%)^{4}$ & $9.041(4.111+4.716+214)(19,47 \%)^{6}$ & 46.429 \\
\hline UFRGS & $26.980(75,47 \%)^{3}$ & $8.768(3.838+4.718+221)(24,53 \%)^{6}$ & 35.748 \\
\hline UFMG & $32.103(82,12 \%)^{3}$ & $6.989(3.052+3.776+161)(17,88 \%)^{6}$ & 39.092 \\
\hline UERJ & $26.145(86,26 \%)^{5}$ & $4.164(1.908+1.957+299)(13,74 \%)^{6}$ & 30.309 \\
\hline UFBA & $27.789(85,50 \%)^{3}$ & $4.714(2.248+2.127+339)(14,50 \%)^{6}$ & 32.503 \\
\hline UFPR & $26.666(87,56 \%)^{3}$ & $3.790(2.349+976+465)(12,44 \%)^{6}$ & 30.456 \\
\hline UFSC & $26.454(81,10 \%)^{3}$ & $6.167(2.804+3.088+275)(18,90 \%)^{6}$ & 32.621 \\
\hline UFSCar & $11.332(77,97 \%)^{3}$ & $3.201(1.451+1.489+261)(22,03 \%)^{6}$ & 14.533 \\
\hline UFV & $13.537(84,70 \%)^{3}$ & $2.445(1.217+1.156+72)(15,30 \%)^{6}$ & 15.982 \\
\hline UnB & $31.348(83,75 \%)^{3}$ & $6.083(2.907+2.863+313)(16,25 \%)^{6}$ & 37.431 \\
\hline Unifesp & $9.589(73,68 \%)^{3}$ & $3.425(1.615+1.491+319)(26,32 \%)^{6}$ & 13.014 \\
\hline
\end{tabular}

Legenda: M - Mestrado; D - Doutorado; MP - Mestrado Profissional.

Fonte: ${ }^{1}$ USP (2015); ${ }^{2}$ UNICAMP (2015); 3Instituto Nacional de Estudos e Pesquisas Educacionais Anísio Teixeira - INEP (2015); ${ }^{4}$ UNESP (2015); ${ }^{5}$ UERJ (2015); ${ }^{6}$ Coordenação de Aperfeiçoamento de Pessoal de Nível Superior - (CAPES, 2015).

Considerando as UCMs, tem-se um percentual médio de 76,49 de alunos de graduação e $23,51 \%$ de pós-graduação $(\mathrm{dp}=5,37)$. No grupo das universidades com potencial, o percentual médio de alunos de graduação é 82,57 e de pós-graduação é 17,43 (dp=4,71). Ambos os grupos passaram no teste de normalidade de KS e SW (p>0,10). Através do Teste T de Studant, constatou-se diferenças significativas entre as médias dos grupos $(\mathrm{p}<0,05)$, ou seja, um maior percentual de alunos de pós-graduação influencia positivamente na obtenção da condição de UCM. No grupo das UCMs, considerando as universidades do Estado de São Paulo, têm-se um percentual ainda maior de alunos de pós-graduação $(26,31 \%$; dp=6,07), o que explica o posicionamento das mesmas nos diferentes rankings.

No quadro 15 é apresentado o orçamento de 2014 das universidades consolidadas como Classe Mundial (públicas) e custo anual aproximado do aluno. Para a análise, considerou-se o número de alunos de graduação e de pós-graduação no ano de 2014 e os respectivos percentuais no total. Os alunos do Ensino a Distância (EaD) não foram computados. Evidentemente, quando se trabalha com orçamento, tem-se um dado impreciso. Nem sempre os valores constantes do orçamento são os efetivamente liberados. Com essa perspectiva, optou-se em utilizar o termo aproximado. Ademais, mesmo sendo a principal fonte de financiamento das universidades públicas, o orçamento não é a única fonte. Com efeito, o custo anual do aluno é, cumprido integralmente o orçamento, superior ao valor 
apresentado, e em função disso, mesmo apresentando valores exatos, optou-se por utilizar o termo aproximado. Ressalta-se também que os orçamentos das universidades federais e estaduais são conformados com critérios distintos. Pegando como exemplo as universidades federais, verifica-se que o número total de alunos não é uma variável utilizada na composição da matriz orçamentária. Utiliza-se o aluno equivalente (considerando o curso realizado) e um conjunto de outras variáveis como: curso novo, duração padrão, fator de retenção, turno, sede, número de ingressantes e concluintes.

Quadro 15 - Orçamento 2014 e custo anual aproximado do aluno das universidades brasileiras de Classe Mundial e com potencial para se tornarem de Classe Mundial

\begin{tabular}{|c|c|c|}
\hline UNIVERSIDADE & $\begin{array}{c}\text { ORÇAMENTO 2014 (EM BILHÃO } \\
\text { DE REAIS) }\end{array}$ & $\begin{array}{c}\text { CUSTO ANUAL APROXIMADO DO } \\
\text { ALUNO (EM REAL) }\end{array}$ \\
\hline USP & $5,029500^{1}$ & $60.937,05$ \\
\hline UNICAMP & $2,195800^{1}$ & $80.983,99$ \\
\hline UFRJ & $2,358770^{2}$ & $47.462,07$ \\
\hline UNESP & $2,344700^{1}$ & $50.500,76$ \\
\hline UFRGS & $1,381441^{2}$ & $38.643,87$ \\
\hline UFMG & $1,542242^{2}$ & $39.451,60$ \\
\hline UERJ & $1,130000^{3}$ & $37.282,66$ \\
\hline UFBA & $1,125007^{2}$ & $34.612,41$ \\
\hline UFPR & $1,114517^{2}$ & $36.594,33$ \\
\hline UFSC & $1,099516^{2}$ & $33.705,77$ \\
\hline UFSCAR & $0,472771^{2}$ & $32.530,86$ \\
\hline UFV & $0,647019^{2}$ & $40.484,23$ \\
\hline UnB & $1,575450^{2}$ & $42.089,44$ \\
\hline Unifesp & $0,720846^{2}$ & $55.390,04$ \\
\hline
\end{tabular}

Fonte: ${ }^{1}$ SÃO PAULO (2014); ${ }^{2}$ INEP (2015); ${ }^{3}$ UERJ (2015).

O custo médio anual do aluno nas universidades de Estado de São Paulo (R\$ 64.140,60; $\mathrm{dp}=15.492,06$ ) é maior que nas universidades federais ( $\mathrm{R} \$$ 40.096,46; $\mathrm{dp}=6.953,92$ ). Submetendo os grupos aos testes de normalidade, os valores das universidades do Estado de São Paulo não passaram no teste de normalidade de KS, mas passaram no teste de normalidade de SW. Com a utilização do teste não-paramétrico de Mann-Whitney, confirma-se a existência de diferenças significativas $(\mathrm{p}=0,0140 ; \mathrm{p}<0,05)$ entre os grupos estabelecidos.

$\mathrm{Na}$ composição do orçamento, os valores despendidos com pessoal, principalmente ativo, são os mais representativos. Para ilustrar, no Quadro 16 é apresentada a composição dos orçamentos das federais no ano de 2014, a Lei Orçamentária Anual (LOA) 2014 e o executado em 2013. 
Quadro 16 - Composição do orçamento 2014, LOA 2014 e valores executados do orçamento 2013

\begin{tabular}{|c|c|c|c|c|c|c|}
\hline IES & $\begin{array}{c}\text { PESSOAL } \\
\text { ATIVO 2014 }\end{array}$ & $\begin{array}{c}\text { PESSOAL } \\
\text { INATIVO 2014 }\end{array}$ & $\begin{array}{c}\text { ORÇAMENTO, } \\
\text { DESPESAS E } \\
\text { CUSTEI 2014 }\end{array}$ & $\begin{array}{c}\text { INVESTIMENTO } \\
\mathbf{2 0 1 4}\end{array}$ & LOA 2014 & $\begin{array}{c}\text { EXECUTADO EM } \\
\mathbf{2 0 1 3}\end{array}$ \\
\hline UFRJ & 1.095 .754 .119 & 760.622 .706 & 447.386 .650 & 55.007 .332 & 2.358 .770 .807 & 2.385 .861 .692 \\
\hline UFRGS & 664.429 .117 & 423.839 .775 & 239.175 .319 & 53.997 .548 & 1.381 .441 .759 & 1.326 .283 .799 \\
\hline UFMG & 716.942 .678 & 447.367 .793 & 296.318 .670 & 81.613 .011 & 1.542 .242 .152 & 1.510 .769 .135 \\
\hline UFBA & 508.586 .264 & 370.877 .915 & 204.818 .476 & 40.725 .087 & 1.125 .007 .742 & 1.122 .106 .987 \\
\hline UFPR & 506.084 .232 & 328.415 .064 & 216.405 .761 & 63.612 .050 & 1.114 .517 .107 & 1.054 .627 .468 \\
\hline UFSC & 531.460 .046 & 284.449 .302 & 225.728 .479 & 57.879 .044 & 1.099 .516 .871 & 1.056 .348 .781 \\
\hline UFSCAR & 268.695 .530 & 66.858 .298 & 80.991 .128 & 56.227 .021 & 472.771 .977 & 470.075 .208 \\
\hline UFV & 344.305 .091 & 159.136 .243 & 105.151 .834 & 38.426 .654 & 647.019 .822 & 645.691 .086 \\
\hline UNB & 701.716 .177 & 252.431 .868 & 509.216 .183 & 112.086 .657 & 1.575 .450 .885 & 1.685 .383 .780 \\
\hline UNIFESP & 415.841 .792 & 138.870 .416 & 96.380 .198 & 69.753 .868 & 720.846 .274 & 702.610 .918 \\
\hline
\end{tabular}

Fonte: INEP (2015).

Considerando as universidades federais estudadas, tem-se que, em média, o pessoal ativo corresponde a $\mathrm{R} \$ 575.381 .504,60(\mathrm{dp}=235.442 .900,00 ; 47,80 \%)$, o pessoal inativo a $\mathrm{R} \$$ 323.286.938,00 ( $\mathrm{dp}=197.849 .567,00 ; 26,86 \%)$, o orçamento, despesas e custeio a $\mathrm{R} \$$ 242.157.269,80 (dp=143.257.775,00; 20,11\%) e investimento a $\mathrm{R} \$ \mathbf{6 2 . 9 3 2 . 8 2 7 , 2 0}$ $(\mathrm{dp}=21.392 .973,00 ; 5,23 \%)$. Somado o valor do pessoal ativo com o inativo, tem-se um percentual de aproximadamente $75 \%$ de gastos com a folha de pagamento.

A situação não é diferente nas três universidades paulistas que apresentam altos níveis de comprometimento do orçamento com a folha de pagamento. Desde 1989, as universidades do Estado de São Paulo, diferentemente das universidades federais, possuem autonomia da gestão financeira. Os orçamentos são vinculados com um percentual da arrecadação líquida do Estado, estipulado anualmente pelo executivo estadual e aprovado pela Assembleia Legislativa (atualmente, 9,57\% do Imposto sobre Circulação de Mercadorias e Serviços ICMS). Na USP, historicamente, o gasto dos seus repasses com a folha de pagamento é de 85\%. Esse percentual, em períodos de queda de arrecadação do Estado de São Paulo, chega a ultrapassar os $100 \%$ do orçamento. Mesmo com um comprometimento pouco menor, a situação da Unicamp e da UNESP é bastante similar.

Ainda que convivam com o mesmo quadro de comprometimento do orçamento com a folha de pagamento das federais, o modelo de autonomia, único no Brasil, permitiu que as universidades do Estado de São Paulo se expandissem e alcançassem níveis de excelências no ensino e na pesquisa, com riscos reduzidos na gestão administrativa e financeira. Mesmo o comprometimento sendo um problema, é necessário ter em vista que a condição de UCM das universidades paulistas deve-se muito a sua capacidade de retenção em seus quadros das melhores mentes. E a retenção é feita, principalmente, com condições de trabalho e remuneração mais elevada. 


\section{Considerações Finais}

As universidades brasileiras na categoria de Classe Mundial consolidadas, segundo os critérios deste estudo, são a USP, a Unicamp e a UFRJ, as em consolidação são a UNESP, a UFRGS e a UFMG. A tendência ascendente e descente das universidades brasileiras se manterem na condição de UCM foi analisada a partir do movimento das posições das universidades, no recorte temporal de 2011 a 2015, classificadas no Ranking Geral da ARWU, no Ranking Global da THE e no Ranking Mundial da QS. A UNESP, a UFRGS e a UFRJ têm tendência ascendente, já a USP, a Unicamp e a UFMG têm tendência descendente. Revelou-se que 11 universidades brasileiras (PUC-RJ, PUC-RS, UERJ, UFBA, UFPR, UFSC, UFSCar, UTV, UnB, PUC-SP e a Unifesp) têm potencial para atingir a condição de UCM. 100\% das UCM brasileiras são públicas, com média de idade de 72 anos e com 76,49\% de alunos na graduação e 23,51\% na pós-graduação. O orçamento anual em 2014 da Unicamp somado ao da UFRJ não chega ao da USP, entretanto, o custo anual do aluno na Unicamp atinge quase 81 mil reais, enquanto que na USP o valor é quase 61 mil e na UFRJ esse valor fica próximo a 88 mil reais. O estado de São Paulo apresenta o maior percentual de alunos de pós-graduação e um nível mais elevado de investimento (custo anual por aluno), sugerindo que essas variáveis marcam mais robustamente o perfil de condição de UCM brasileira.

Considerando-se que os rankings, enquanto instrumentos avaliativos, apresentam enfoque nivelador, e considerando que o contexto atual das instituições de ensino envolve estar presente nos rankings, a crítica mercadologica dos rankigns pode ser atenuada se o controle e a avaliação, como atribuição de valor e produção de sentido educacional, estiverem trabalhando juntos para avaliação educativa. Assim, pesquisas institucionais precisam ser divulgadas em periódicos indexados em base de dados como a SCIE, a SSCI, a Thomson Reuters e o Scopus, é ali que as UCM publicam.

\section{Referências}

ARWU. Academic Ranking of World Universities 2015 Press Release. Shanghai: People's Republic of China, 2015a. Disponível em: <http://www.shanghairanking.com/AcademicRanking-of-World-Universities-2015-Press-Release.html>. Acesso em: 24 ago. 2015.

ARWU. Methodology: Ranking criteria and weights. Shanghai: People's Republic of China, 2015b. Disponível em: <http://www.shanghairanking.com/ARWU-Methodology-2015.html>. Acesso em: 6 out. 2015. 
ARWU. Academic Ranking of World Universities. Shanghai: People's Republic of China, 2015c. Disponível em: <www.shanghairanking.com/ARWU2015.html>. Acesso em: 28 dez. 2015.

BENGOETXEA, Endika; BUELA-CASAL, Gualberto. The new multidimensional and userdriven higher education ranking concept of the European Union. International Journal of Clinical and Health Psychology, Toronto, v. 13, n. 1, p. 67-73, 2013.

BARREYRO, Gladys Beatriz. De exames, rankings e mídia. Avaliação, Campinas; Sorocaba, v. 13, n. 3, p. 863-868, nov. 2008.

BOTHWELL, Ellie. World Academic Summit in Melbourne: more speakers annoucend.

Times Higher Education, London, 6 Aug. 2015a. Disponível em:

$<$ https://www.timeshighereducation.co.uk/world-academic-summit-melbourne-morespeakers-announced>. Acesso em: 31 ago. 2015.

BOTHWELL, Ellie. World Universiy Ranking 2015-2016 results coming. Times Higher Education, London, 30 Sept. 2015b. Disponível em: $<$ https://www.timeshighereducation.co.uk/news/world-university-rankings-2015-2016results-coming-30-september>. Acesso em: 31 ago. 2015.

CALDERÓN, Adolfo; PFISTER, Mariana; FRANÇA, Carlos Marshal. Rankings acadêmicos na educação superior brasileira: a emergência de um campo de estudo (1995-2013). Roteiro, Joaçaba, SC, v. 40, n. 1, p. 11-30, 2015.

CHEN, Kuang-hua; LIAO, Pei-yu. A compartive study on word university ranking: a bibliometric survey. Scientometrics, Budapest, v. 92, n. 1, p. 89-103, 2006.

COORDENAÇÃO DE APERFEIÇOAMENTO DE PESSOAL DE NÍVEL SUPERIOR (CAPES). Dados do SNPG (2014). Brasília: CAPES, 2015. Disponível em: <http://www.capes.gov.br/avaliacao/dados-do-snpg>. Acesso em: 21 nov. 2015.

CUNHA, Luiz Antônio. A universidade temporã: o ensino superior da colônia à era de Vargas. Rio de Janeiro: Civilização Brasileira, 1980.

DIAS SOBRINHO, José. Avaliação ética e política em função da educação como direito público ou como mercadoria? Educação e Sociedade, Campinas, v. 25, n. 88, p. 703-725, out. 2004.

DIAS SOBRINHO, José. Qualidade, avaliação: dos SINAES a Índices. Avaliação, Campinas; Sorocaba, v. 13, n. 3, p. 817-825, nov. 2008.

HUANG, Mu-Hsuan. Opening the black box of QS World University Rankings. Research Evolution, Oxford, v. 21, n. 1, p. 71-78, 2012.

INSTITUTO NACIONAL DE ESTUDOS E PESQUISAS EDUCACIONAIS ANÍSIO TEIXEIRA (INEP). Censo Superior 2014. Brasília: INEP, 2015. Disponível em: $<$ http://download.inep.gov.br/educacao_superior/censo_superior/documentos/2015/notas_sob re_o_censo_da_educacao_superior_2014.pdf>. Acesso em: 21 nov. 2015.

NASSI-CALÒ, L. Indicadores de produtividade científica em rankings universitários: critérios e metodologias. SciELO em Perspectiva. 2013. Disponível em: $<$ http://blog.scielo.org/blog/2013/08/15/indicadores-de-produtividade-cientifica-em-rankingsuniversitarios-criterios-e-metodologias>. Acesso em: 24 ago. 2015.

ORDORIKA, Imanol; RODRIGUEZ GOMES, Roberto. El ranking Times em el mercado del prestigio universitário. Perfiles Educativos, México, v. 32, n. 129, p. 08-29, 2010. 
POBLETE, Orlando. El valor de los rankings de instituciones de educación superior. In.: Calidade em la Educación, Santiago, n. 25, p. 99-105, 2006.

QS. WORLD UNIVERSITY RANKINGS: Methodology. London, Sept. 2015a. Disponível em: <http://www.topuniversities.com/university-rankings-articles/world-universityrankings/qs-world-university- rankings-methodology>. Acesso em: 11 out. 2015.

QS. WORLD UNIVERSITY RANKINGS: Quacquarlli Symonds. Inclusion in Rankings, London, 2015b. Disponível em: <http://www.iu.qs.com/university-rankings/policiesconditions>. Acesso em: 07 nov. 2015.

QS. WORLD UNIVERSITY RANKINGS 2015/16. London, 2015c. Disponível em: $<$ http://www.topuniversities.com/university-rankings/world-universityrankings $/ 2015 \#$ sorting $=$ rank + region $=+$ country $=+$ faculty $=+$ stars $=$ false + search $=>$. Acesso em: 8 dez. 2015.

QS. UNIVERSITY RANKINGS BRICS 2015. London, 2015d. Disponível em: http://www.topuniversities.com/brics-rankings Acesso em: 28 dez. 2015.

QS. UNIVERSITY RANKINGS LATIN AMERICA 2016. London, 2016. Disponível em: $<$ http://www.topuniversities.com/university-rankings/latin-american-universityrankings $/ 2016 \#$ sorting $=$ rank + region $=+$ country $=+$ facult $=+$ stars $=$ false + search $=>$. Acesso em: 8 jan. 2016.

ROBINSON-GARCÍA, Nicolas et al. Na insight into the importance of national university rankings in an international context: the cade of the I-UGR ranking of Spanish universities. Scientometrics, Budapest, v. 101, n. 2, p. 1309-1324, 2014.

SANTOS, Solange Maria dos. O desempenho das universidades brasileiras nos rankings internacionais: áreas de destaque da produção científica brasileira. 2015. 344 p. Tese (Doutorado em Cultura e Informação) - Escola de Comunicações e Artes, Universidade de São Paulo, São Paulo, 2015. Disponível em:

<www.teses.usp.br/teses/disponiveis/27/27151/tde-26052015-122043>. Acesso em: 29 jul. 2015.

SÃO PAULO. GOVERNO DO ESTADO DE SÃO PAULO. Orçamento do Estado 2014. São Paulo: Secretaria de Planejamento e Desenvolvimento Regional, 2014. Disponível em: <http://www.planejamento.sp.gov.br/noti_anexo/files/orcamento/Orcamento_2014.pdf >. Acesso em: 21 nov. 2015.

SCHWEKENDIEK, Daniel. Recent chances in World University Ranking: an explorative study of Korea and Germany. Asia Europe Journal, Singapore, v. 13, n. 4, p. 361-377, 2015.

SURSOCK, Andrée; SMIDT, Hanne. Trends 2010: a decade of change in European Higher Education. Brussels, Belgium: European University Association, 2010.

TAN, Yao Sua; GOH, Soo Khoon. International Students, academic publications and world rankings: the impact of globalization and responses of a Malaysian Public University. Higher Education: The International Journal of Higher Education and Educational Planning, Washington, v. 68, n. 4, p. 489-502, 2014.

THE. World University Ranking 2015-2016. Methodology about. London, 2015a. Disponível em: 〈https://www.timeshighereducation.com/news/ranking-methodology-2016>. Acesso em: 3 nov. 2015.

THE. World University Ranking 2015-2016 methodology. Change for the better: fuelled by more comprehensive data, the 2015-1016 rankings probe deeper than ever. London, Sept., 24, 
2015b. Disponível em: <https://www.timeshighereducation.com/news/ranking-methodology2016>. Acesso em: 07 out. 2015.

THE. World University Ranking. London, 2015c. Disponível em: https://www.timeshighereducation.com/world-university-rankings/2016/worldranking\#!/page/0/length/25/sort_by/rank_label/sort_order/asc/cols/rank_only Acesso em $10 / 11 / 2015$

UNIVERSIDADE DE SÃO PAULO (USP). USP em números 2015. São Paulo: USP, 2015. Disponível em: <http://www.usp.br/internationaloffice/index.php/midia/numeros/>. Acesso em: 21 nov. 2015.

UNIVERSIDADE DO ESTADO DO RIO DE JANEIRO (UERJ). Data UERJ 2015: anuário estatístico base de dados 2014. Rio de Janeiro: UERJ, 2015. Disponível em: <http://www2.datauerj.uerj.br/pdf/DATAUERJ_2015.pdf>. Acesso em: 21 nov. 2015.

UNIVERSIDADE ESTADUAL DE CAMPINAS (UNICAMP). Anuário estatístico 2015: base 2014. Campinas: Unicamp, 2015. Disponível em: <http://www.aeplan.unicamp.br/anuario/anuario_2015.php>. Acesso em: 21 nov. 2015. UNIVERSIDADE ESTADUAL PAULISTA “JÚLIO DE MESQUITA FILHO” (UNESP). Anuário estatístico 2015. São Paulo: UNESP, APE, 2015. Disponível em: <https://ape.unesp.br/anuario/>. Acesso em: 21 nov. 2015.

USHER, Alex; SAVINO, Massimo. Estudo global de los rankings universitários. Calidad en la Educación, Santiago, n. 25, p. 31-53, 2006.

VALLE, Aldo. Idoneidad de los rankings universitários. Calidad en la Educación, Santiago, n. 25, p. 109-126, 2006.

VINCKE, Philippe. Les classements d'universités. Pyramides, Bruxelles, v. 14, p. 71-94, 2012.

Luiz Alberto Pilatti Universidade Tecnológica Federal do Paraná | Programa de Pós-Graduação em Ensino de Ciência e Tecnologia Ponta Grossa | PR | Brasil. Contato: lapilatti@utfpr.edu.br

(iD) http://orcid.org/0000-0003-2679-9191

Marizete Righi Cechin Universidade Tecnológica Federal do Paraná | Programa de Pós-graduação em Ensino de Ciência e Tecnologia Ponta Grossa | PR | Brasil. Contato: mrcechin@utfpr.edu.br

(iD) http://orcid.org/0000-0001-7651-8082

Artigo recebido em 27 de julho de 2016 e aprovado em 6 de junho de 2017. 